Proceedings of XIX International Scientific Conference "New Technologies and Achievements in Metallurgy, Material Engineering, Production Engineering and Physics", Częstochowa, Poland, June 7-8, 2018

\title{
The Effect of Welding Methods on the Corrosion Resistance of 304 Stainless Steel Joints
}

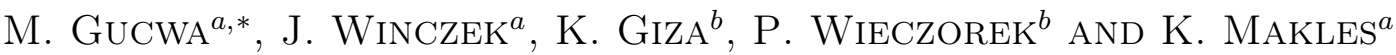 \\ ${ }^{a}$ Częstochowa University of Technology, Faculty of Mechanical Engineering and Computer Science, \\ Institute of Mechanical Technologies \\ ${ }^{b}$ Częstochowa University of Technology, Faculty of Production Engineering and Materials Technology, \\ Institute of Materials Engineering
}

\begin{abstract}
This paper describes the study of corrosion resistance of 304 stainless steel joint welded with different heat input in the material. The welding was done with classic methods and their low energy varieties. The structure and properties of austenitic steels joints strongly depend on the level of heat input in the material. Electrochemical corrosion resistance tests were carried out in $5 \% \mathrm{NaCl}$ solution. The obtained results show the decrease of corrosion resistance of tested joints in comparison to the base material.
\end{abstract}

DOI: 10.12693/APhysPolA.135.232

PACS/topics: welding, stainless steel, structure, corrosion

\section{Introduction}

Stainless steels are an important group of engineering materials that are widely used in a variety of industries and environments due to good mechanical properties and corrosion resistance. Austenitic stainless steels, due to excellent properties such as corrosion resistance, ductility, toughness, and weldability, represent the largest general groups of stainless steels, which are produced in higher tonnages than any other groups. The gas metal arc welding (GMAW) method, which is the most popular arc welding process by reason of a wide range of applications, is not without drawbacks. A large amount of heat input to the material adversely affects the properties of the welded joint and is problematic in welding thin-walled elements (thickness $<2 \mathrm{~mm}$ ) because of thermal deformation. Another issue related to welding is aesthetics - spatter contamination adjacent to the joint surfaces require removal, which is labor-intensive, affects the efficiency and complicates the technological processes accompanying the production. Spatter is accompanied by emissions of gases and dust that negatively affect the working environment. In addition, welding of dissimilar metal joints and joining elements coated with metallic coatings were a big problem. As a result of intensive research, each of the significant producers of welding sources proposed its alternative version of the GMAW method, with low heat input, low spatter and controlled short circuit transfer $[1,2]$. This is how cold metal transfer (CMT) was created by Fronius, ColdArc ${ }^{\circledR}$ by EWM, surface tension transfer (STT) - Lincoln Electric, Speed Cold and Speed Root by Lorch. The common denominator for all these methods is to reduce the total en-

\footnotetext{
* corresponding author
}

ergy input during welding. The low energy course of the welding process also results in the use of a short arc to make the joint using a small diameter welding wire (about 1-1.2 mm). Due to the smaller amount of heat supplied to the joint, these methods seem to be attractive also in the case of combining stainless steels, and in particular steel with austenitic structure. Reducing the amount of heat brought to the joint should have a positive effect on the structure, limiting the size of the heat zone and structural changes such as the amount of $\delta$ ferrite, sigma phase or chromium carbides responsible for corrosion $[3,4]$. The important factor of the quality of the joints is the filler materials for example type $316 \mathrm{~L}$ gives the needle-shaped structure of acicular ferrite that improve tensile properties in weld metal (WM) [5]. A structure and chemical composition of WM is the key part of the whole joint and its corrosion resistance, depending on the method of welding and materials combination $[6,7]$.

The main purpose of this work was to examine the influence on corrosion resistance of the low energy method of welding as Speed Cold and Speed Root and compare them with the classical GMAW method.

\section{Methods}

Stainless steel grade 304 (X5CrNi18-10) with austenitic structure was selected for welding tests. All steel plates with dimensions $300 \times 150 \times 2 \mathrm{~mm}^{3}$ were prepared for welding butt joint in flat position. The welding source was LORCH S-XT with possibility of setting different mode of welding as marked P33 (Puls), P39 (Synergic), P223 (Speed Cold) and P214 (Speed Root). For making joints, a solid wire LNM 316LSi (Lincoln Electric) with a diameter of $1 \mathrm{~mm}$ was used for each welding method. Each time, the gas shield was a gas mixture $\left(97.5 \% \mathrm{Ar}+2.5 \% \mathrm{CO}_{2}\right)$. The welding 
parameters are shown in Table I. After the welding of the samples, individual fragments were cut out with the division into joint zones: WM, heat affected zone (HAZ) with base metal and the entire joint across the base material, HAZ, and the weld. Water cutting type was used due to the avoidance of heating the material which is connected with the possible change of the structure of individual joint zones. The device used for the cutting process is a KIMLA machine of the StreamCut 3116 type. The prepared samples were tested with optical microscope Olympus GX51. Electrochemical tests were carried out in a $5 \% \mathrm{NaCl}$ solution (solution in contact with air) at the temperature of $25^{\circ} \mathrm{C}$ by means of an electrochemical measuring station ( $\mathrm{CH}$ Instruments 1140A USA) controlled by a computer. As an auxiliary electrode, a platinum electrode was used in the form of a spiral, and as a reference electrode - a saturated calomel electrode (SCE). Before each measurement, the samples were grounded on aqueous abrasive papers with finer and smaller grains (up to 1200), and then rinsed with distilled water. Electrochemical measurements used to assess the susceptibility of the tested areas of welded joints to galvanic corrosion were performed by recording the open circuit potential (OCP) values against SCE. In order to estimate the corrosion rate of the tested materials, the polarization curves in the anodic direction were recorded at the scanning rate of the potential of $1 \mathrm{mV} / \mathrm{s}$, assuming an initial value of the potential of about $200 \mathrm{mV}$ lower than OCP. Polarization curves were recorded under identical initial conditions after $60 \mathrm{~min}$ from the moment the sample was immersed in the working solution. Three replicates were made for each electrode. The most representative measurement was selected.

TABLE I

The welding parameters.

\begin{tabular}{c|c|c|c|c|c}
\hline \hline $\begin{array}{c}\text { Sample } \\
\text { no. }\end{array}$ & $\begin{array}{c}\text { Welding } \\
\text { programme }\end{array}$ & $\begin{array}{c}\text { Welding } \\
\text { speed } \\
{[\mathrm{mm} / \mathrm{s}]}\end{array}$ & $\begin{array}{c}\text { Welding } \\
\text { current } \\
{[\mathrm{A}]}\end{array}$ & $\begin{array}{c}\text { Welding } \\
\text { voltage } \\
{[\mathrm{V}]}\end{array}$ & $\begin{array}{c}\text { Heat } \\
\text { input } \\
{[\mathrm{kJ} / \mathrm{mm}]}\end{array}$ \\
\hline 1 & P33 & 5 & 76 & 19.1 & 0.29 \\
2 & P39 & 7.5 & 134 & 19.3 & 0.34 \\
3 & P223 & 7.5 & 135 & 21.0 & 0.38 \\
4 & P214 & 7.5 & 128 & 21 & 0.27 \\
5 & P39 & 7.5 & 149 & 21.1 & 0.42
\end{tabular}

\section{Results and discussion}

The structure of base metal was austenite with small amount of $\delta$-ferrite (Fig. 1). It was observed that there was rising content of the $\delta$-ferrite in the structure of $\mathrm{HAZ}$ in every sample in comparison to the base metal. The structure in fusion line were austenite with vermicular and lathy ferrite. There were significant changes in the morphology of the fusion area depending on the heat input (Fig. 2). With the increasing heat input ferrite

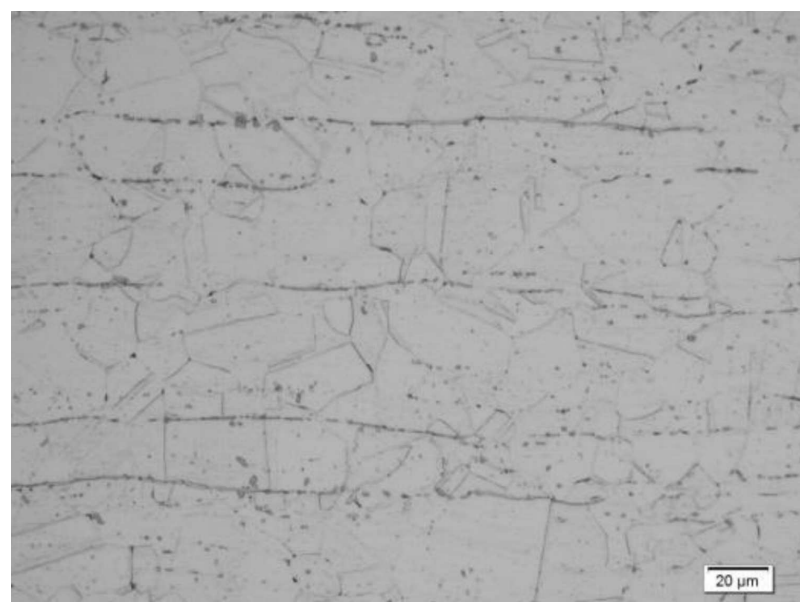

Fig. 1. Structure of base metal, steel grade 304 .
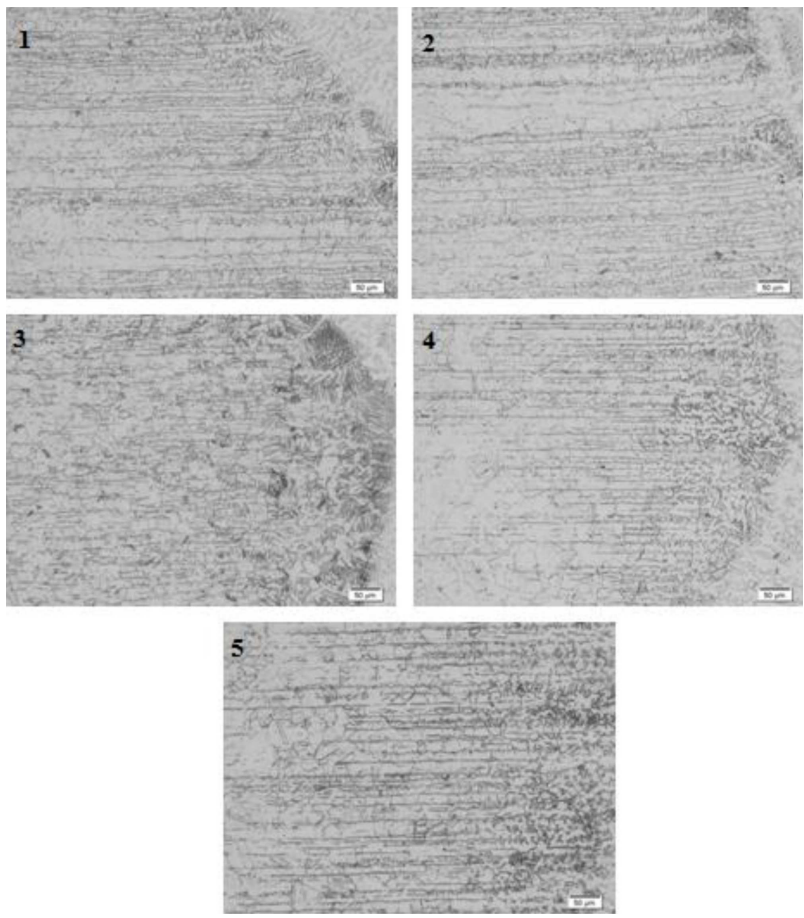

Fig. 2. The structure of fusion line and heat affected zone.

amount in the structure increased. Generally, in all samples $\delta$-ferrite is classified into lathy and vermicular shape which is caused by heat input. The ferrite from fusion line is transformed in the line shape precipitations in the heat affected zone in parallel to rolling direction. For the lower heat inputs this character of the ferrite precipitation is observed on the smaller distance from the fusion line. The weld metal in all the samples was skeletal morphology of ferrite in matrix of austenite (Fig. 3). Ferrite was precipitated in the interdendritic area and was classified as in the fusion area. It was found that with the increasing heat input the proportion of the vermicular and lathy ferrite changes. Samples welded with lower heat input were rich in vermicular ferrite opposite to sam- 

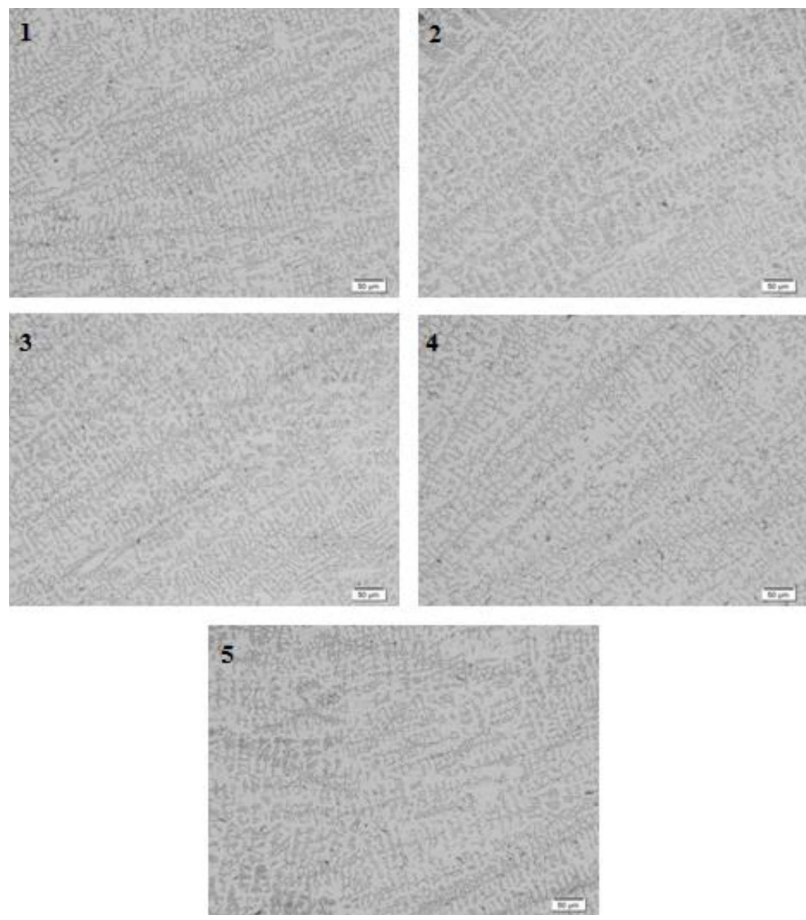

Fig. 3. Structure of weld metal for all samples.

ples within the amount of vermicular ferrite decreased for higher portion of lathy ferrite. The lower heat input caused relatively higher thermal gradients in the weld metal. There was reason of the finer ferrite dendrite size and bigger spacing between dendrites. The higher heat input resulted in slower cooling and longer time available for the dendrites to grow.

The creation of passive film is one of the main properties of stainless steels. The problem is that the structural and chemical composition heterogeneity during weld metal solidification may significantly change the quality of the passive film and then the corrosion behavior of the welded metal. According to Fig. 4, the current density

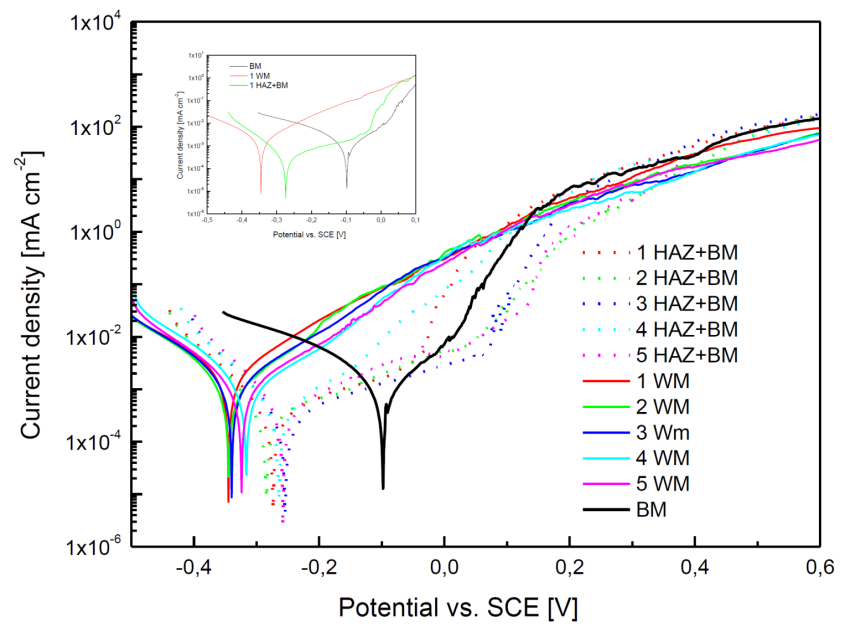

Fig. 4. Potentiodynamic polarization curves of the $\mathrm{BM}, \mathrm{HAZ}$, and $\mathrm{VM}$ in $\mathrm{NaCl}$ solution at $25^{\circ} \mathrm{C}$. for base metal was almost on the same level as for the whole investigated weld metals. There is one exception in sample No. 2 in which the value of current density was significantly higher but still low (Table II). The current density of the heat affected zones and base metal were higher in comparison to the base metal and sample No. 2 had the highest value, too (Table III). The similar current density in all investigated regions suggest low segregation of element which improves corrosion resistance. If the chromium content is higher in $\delta$-ferrite than in austenite phase, the corrosion resistance is improved [8]. However, the presence of $\delta$-ferrite with higher chromium content may have detrimental effect on the corrosion resistance due to the potential difference between the $\delta$-ferrite and austenite phases [9]. The base metal has higher corrosion potential than the welded metal and heat affected zone for all samples. In this situation, when the joint is placed in the electrolyte, the welded metal is anodic of the galvanic couple between base metals and welded metals. Since the heat affected zones have a little better corrosion potential, near the base metal, the welds are more sensitive to corrosion (Fig. 4). There was no significant difference in the corrosion potential in the researched samples but samples No. 3 which was welded with low energy method was characterized by the most favorable corrosion parameters.

TABLE II

Electrochemical corrosion parameters for WM compared to base metal (BM).

\begin{tabular}{c|c|c|c|c|c|c}
\hline \hline & BM & WM 1 & WM 2 & WM 3 & WM 4 & WM 5 \\
\hline$I_{\text {corr }}\left[\mathrm{A} / \mathrm{cm}^{2}\right]$ & 0.0011 & 0.0016 & 0.0024 & 0.0015 & 0.0013 & 0.0013 \\
$E_{\text {corr }}[\mathrm{V}]$ & -0.10 & -0.34 & -0.35 & -0.34 & -0.32 & -0.32
\end{tabular}

TABLE III

Electrochemical corrosion parameters for HAZ compared to BM.

\begin{tabular}{c|c|c|c|c|c|c}
\hline \hline & BM & $\begin{array}{c}\text { HAZ 1 } \\
+ \text { BM }\end{array}$ & $\begin{array}{c}\text { HAZ 2 } \\
+ \text { BM }\end{array}$ & $\begin{array}{c}\text { HAZ 3 } \\
+ \text { BM }\end{array}$ & $\begin{array}{c}\text { HAZ 4 } \\
+ \text { BM }\end{array}$ & $\begin{array}{c}\text { HAZ 5 } \\
+ \text { BM }\end{array}$ \\
\hline$I_{\text {corr }\left[\mathrm{A} / \mathrm{cm}^{2}\right]}$ & 0.0011 & 0.00032 & 0.00069 & 0.00022 & 0.00041 & 0.00037 \\
$E_{\text {corr }}[\mathrm{V}]$ & -0.10 & -0.27 & -0.28 & -0.25 & -0.26 & -0.26
\end{tabular}

\section{Summary}

1. There were no significant differences in the corrosion resistance, in researched condition, for investigated welding methods. The low energy method as Speed Cold (sample No. 3) has the advantageous parameters of corrosion resistance, but differences with the rest method are subtle. There is not significant advantage in using low energy methods and corrosion resistance.

2. The morphology of the $\delta$-ferrite in welds metal were in the lathy and vermicular form. The bigger heat input caused in increasing content of the lathy shape ferrite and bigger dendrite size. 
3. Due to the fact that the welds were the most sensitive to corrosion in the whole joints it is preferable to choose the filler metal that has the corrosion potential to the base metal.

\section{References}

[1] J. Norrish, D. Cuiuri, J. Manufact. Process. 16, 86 (2014).

[2] A. Scotti, V. Ponomarev, W. Lucas, J. Mater. Process. Technol. 212, 1406 (2012).

[3] M. Gucwa, R. Bęczkowski, A. Grzyb, Archiv. Foundry Eng. 14, 131 (2014).
[4] R. Mohammed, G.M. Reddy, K.S. Rao, Def. Technol. 11, 237 (2015).

[5] M. Shojaati, B. Beidokthi, Construct. Build. Mater. 147, 608 (2017).

[6] R. Unnikrishnan, K.S.N. Satish Idury, T.P. Ismail, A. Bhadauria, S.K. Shekhawat, R.K. Khatirkar, S.G. Sapate, Mater. Character. 93, 10 (2014).

[7] D.J. Lee, J.C. Byun, J.H. Sung, H.W. Lee, Mater. Sci. Eng. A 513, 154 (2009).

[8] G.R. Mirshekari, E. Tavakoli, M. Atapour, B. Sadeghian, Mater. Des. 55, 905 (2014).

[9] C.M. Lin, H.L. Tsai, C.D. Cheng, C. Yang, Eng. Failure Anal. 21, 9 (2012). 